\title{
CONTRIBUIÇÕES DO DESIGN: estratégia para a identificação de novos modelos de negócio para a indústria fonográfica
}

\author{
Juan Pablo Boeira \\ UNISINOS \\ mscjuanpablo@gmail.com \\ Claralucia Prates Machado \\ UNISINOS \\ clara@claramachado.com
}

\section{Resumo:}

Em mercados onde a necessidade de um olhar direcionado para a resolução de problemas complexos e a busca por soluções inovadoras é crescente, destaca-se o Design Estratégico como agregador de função, forma e símbolo ao valor do produto, serviço, comunicação e experiência. Neste contexto, é possível conectar, pela lente do Design Estratégico, os pequenos detalhes a uma visão holística e entender a conexão entre a concepção e a execução de um projeto, fazendo deste, um recurso potencial frente ao presente âmbito mercadológico. Sob este aspecto, o artigo em questão tem como objetivo analisar as contribuições do Design Estratégico para a identificação de novos modelos de negócio para a Indústria Fonográfica a partir da geração de cenários. O artigo conta com uma fundamentação teórica que embasa o estudo, o entendimento do ambiente vivenciado e a aplicação do Design Estratégico, através de observação participante em que avalia formas de identificar os níveis de compreensão dos atores envolvidos e os momentos mais produtivos em relação à resolução do problema proposto. O design, neste sentido, contribuiu com a avaliação das oportunidades face ao suporte empregado nas análises estratégicas, incorporando os riscos e as interferências externas.

Palavras-chave: Design Estratégico, Indústria Fonográfica e Cenários.

\begin{abstract}
:
In markets where the need for a gaze directed toward the resolution of complex problems and the search for innovative solutions is growing, Strategic Design stands out as an aggregator function, form and symbol to the value of the product, service, communication and experience. In this context, it is possible to connect through the lens of Strategic Design, the small details to an holistic vision and understand the connection between the Design and the execution of a project, making it
\end{abstract}


become a potential resource before the present context marketing. In this regard, the article in question aims to analyze the contributions of Strategic Design for the identification of new business models for the phonographic industry from the generation of scenarios. The article has a theoretical basis that underlies the study, the understanding of the environment experienced and the application of Strategic Design through participant observation evaluating ways to identify the levels of understanding of the actors involved and the most productive moments in regard to the resolution of the problem proposed. The design in this sense contributed to the assessment of opportunities against the used in support strategic analysis, incorporating the risks and external interference.

Key Words: Strategic Design, Phonographic Industry and Scenarios.

\section{INTRODUÇÃO}

A sociedade atual encontra-se em um momento em que as mudanças são a cada instante, mais intensas, rápidas e profundas (AAKER, 2011). Deste modo, segundo o autor, do despertar até o momento de dormir, os indivíduos são impactados diariamente, nos grandes centros, em média, por mais de três mil mensagens. Isso pode significar que tudo o que se sabe hoje sobre determinado assunto, pode, em uma fração de segundos, tornar-se obsoleto ou ultrapassado.

Com o desenvolvimento das formas de consumo, da grande quantidade de informação disponível atualmente e com a evolução da comunicação, surgem novas formas de experiências, sejam sociais, culturais, econômicas ou políticas. Novas dinâmicas de consumo são incorporadas aos processos de produção e utilização dos serviços em todas as suas instâncias e, deste modo, o consumidor passa a demonstrar uma empírica mudança de comportamento (BARROS, 2006).

É neste contexto de mudanças e evoluções, que o segmento da Indústria Fonográfica passa por instabilidades e observa diminuir seus patamares de lucratividade (IFPI, 2014).

Assim, o Design surge como meio para análise deste novo padrão de consumo, atuando de forma multidisciplinar (ZURLO, 2006). Com base neste contexto e a partir do Design Estratégico, é possível levar em consideração que, atualmente, o designer não projeta apenas artefatos desprovidos de significação ou que resolvam apenas problemas funcionais, mas também é capacitado para projetar toda a cadeia de valor do produto - cadeia esta denominada Sistema Produto Serviço (PSS).

Para que fosse possível então o entendimento dos propósitos desta investigação, foi aplicada a perspectiva do Design Estratégico e algumas de suas ferramentas de forma a aproximar uma resposta à questão chave orientadora deste artigo. Deste modo, o presente estudo abordou as definições de Design e Design Estratégico com seus devidos instrumentos de acordo com as suas utilizações. Foram avaliadas a forma particular do design e sua crescente aproximação com as estratégias empresariais, a fim de refletir como a Indústria Fonográfica pode redesenhar sua forma de inserir seus artistas com relevância na cena musical, através da geração de cenários. 
O artigo inicia com uma revisão no manancial teórico que aborda questões relacionadas à base conceitual do design estratégico, do sistema produto serviço (PSS) e da inovação e novos modelos de negócio, seguido pela metodologia, analise e discussão dos resultados da pesquisa chegando-se as considerações finais e referências utilizadas.

\section{DESIGN E DESIGN ESTRATÉGICO}

Pode-se dizer que o Design existe desde os primórdios da humanidade, quando o homem, para suprir suas necessidades básicas criou produtos. A pré-história do Design situa-se na Inglaterra com a emergência da padronização da produção. Foi quando houve a dissociação da concepção do objeto de sua manufatura, que até então, estava incorporado às habilidades de um indivíduo, o artesão (MOZOTA, 2003).

A mecanização imposta pela Revolução Industrial, época em que houve a transição para novos processos de manufatura no período entre 1760 e 1840, gerando a transição de métodos de produção artesanais para a produção por máquinas, possibilitou a reprodução, em série, de artigos úteis e baratos (HOSBSBAWN, 1982).

No entanto, a maior evolução desde 1990, tem sido a relação entre Design e tecnologia. O designer pode agora trabalhar com a aparência externa sem ser controlado pela sua estrutura interna. "Design, arte e artesanato têm muito em comum e hoje, quando o Design já atingiu certa maturidade institucional, muitos designers começam a perceber o valor de resgatar as antigas relações como o fazer manual" (DENNIS, 2000, p.17). Já para Martin (2009, p.58), "Design não é somente fazer coisas bonitas; é também fazer com que as coisas trabalhem maravilhosamente bem" pela prerrogativa de seu processo de projeto. É, portanto, trabalhar com o Design Estratégico.

Neste sentido, através de processos de geração de cenários e de sua capacidade específica de resolução de problemas, o Design Estratégico, mostra-se como uma fonte de produção de soluções inovadoras quando "produtos" e "serviços" não são analisados como elementos separados, mas sim como um conjunto integrado, denominado Sistema Produto Serviço (PSS - Product Service System), (MERONI, 2008).

\section{SISTEMA PRODUTO SERVIÇO - PSS}

As avaliações do Sistema Produto Serviço - PSS buscam substituir as soluções centradas no produto, reestruturando a maneira de satisfazer o consumidor através da associação do bem físico e serviços. O PSS apresenta serviços associados ao produto com a função de desmaterializar o consumo de produtos através da satisfação do consumidor.

De acordo com Borba e Reyes (2007, p.4), “a expressão sistema-produto agrega a expansão do conceito ao aliar os serviços e a experiência ao processo de sua utilização". Nesse sentido, o foco do design antes alimentando a inovação focada em produto ou serviço, é alterado para uma estratégia de design envolvendo todo o sistema-produto focada em soluções. 
Para uma melhor compreensão do posicionamento do PSS, Baines et al. (2007) trazem um comparativo de como os produtos e serviços eram considerados pelos usuários. Antes, de acordo com os autores, as pessoas relacionavam produtos de forma distinta dos serviços. Porém, nos últimos anos, a visão dos usuários estava sendo para "servicização" de produtos e para a "produtização" de serviços. Nesse sentido, é possível perceber que houve uma nova percepção por parte dos usuários no sentindo de aceitar essa nova oferta de forma integradora.

O PSS apresenta então, uma estratégia de inovação, redirecionando a venda de produtos físicos para a venda de sistemas de produtos e serviços que juntos são capazes de atender as necessidades dos clientes (UNEP, 2004).

\section{INOVAÇÃO E INOVAÇÃO EM MODELOS DE NEGÓCIOS}

Karl Marx entendia que o processo de acumulação de capital dependia de inovações em bens de capital e o aprofundamento da divisão social do trabalho. Segundo ele, inovação era vista como "uma forma de obter um monopólio temporário sobre uma técnica superior ou um produto diferenciado". O monopólio seria temporário, pois em pouco tempo o sucesso de tal produto inovador atrairia a concorrência e por consequência imitações, trazendo competição ao mercado, ocasionando a queda no preço de comercialização (TIGRE, 2006).

Schumpeter talvez tenha sido o economista que mais desenvolveu as ideias de Marx sobre a economia capitalista e o papel da tecnologia (TIGRE, 2006). Em 1934 ele defendia a ideia de que as economias capitalistas são sustentadas através do impacto das inovações tecnológicas, em que as novas tecnologias substituem as antigas, ideia que contrapõe a teoria neoclássica. Nesta mesma época propôs uma lista de inovações: de produtos, de métodos de produção, abertura de novos mercados, de novas estruturas de mercado em uma indústria e novas fontes de matéria-prima (SCHUMPETER, 1982).

O progresso econômico movido pelos avanços tecnológicos e o crescimento da inovação, influencia diretamente a evolução das nações, e neste sentido em 1963 surgiu o Manual de Frascati, com o objetivo de criar um sistema padrão para a avaliação em pesquisa e desenvolvimento, organizado pela Organização para Cooperação e Desenvolvimento Econômico - OCDE. Este manual entende a inovação como a transformação de uma ideia em um produto vendível, novo ou melhorado, ou em um processo produtivo ou um novo método de serviço social. Nesta última edição do Manual de Oslo, a inovação é vista como um processo dinâmico em que o conhecimento é acumulado por meio do aprendizado e da interação (MANUAL DE OSLO, 1998, p.41).

Já a inovação em negócios ocorre através de um perfil de organização inovadora (TIDD et al., 2008). A Organização Inovadora vai além da estrutura; trata-se de um conjunto integrado de componentes que trabalham juntos para criar e fortalecer o tipo de ambiente que permita que a mesma prospere.

A geração de modelos de negócio inovadores representa uma nova fonte de vantagem competitiva considerando que pode resultar na criação de valor organizacional e na mudança da forma de fazer negócio, tornando-se um novo padrão para o surgimento de novos empreendedores em busca do sucesso (ZOTT; AMIT; MASSA, 2010). 
Um modelo de negócios inovador bem-sucedido necessita reconhecer a necessidade de migrar o modelo de negócio para um novo modelo à medida que se verifica uma redução de criação valor. Explorar ainda novas oportunidades de criação de valor para o novo modelo e escolhe cuidadosamente os componentes de um modelo de negócio de forma a sustentar a inovação por um longo período (MAHADEVAN, 2002).

\section{METODOLOGIA}

No que tange à estratégia de pesquisa, este trabalho, devido às características não quantificáveis de seu objeto, fez uma avaliação qualitativa, caracterizada pela descrição, compreensão e interpretação de fatos e fenômenos primeiramente através de uma Observação Participante. Tal estratégia mostrou-se plenamente de acordo com as abordagens não convencionais que, segundo Martins e Theóphilo (2009), priorizam as avaliações qualitativas, como é o caso da Observação Participante, definida para o presente estudo.

Escolheu-se a Observação Participante também por incentivar a participação direta e contínua do pesquisador durante um ano de pesquisa participando da cena musical em diversos aspectos do sistema produtivo, o que fez com que os resultados da pesquisa tivessem uma perspectiva mais horizontal e histórica.

Thiollent (1997, p.41) evidencia, ainda, a possibilidade de aplicação da Observação Participante em disciplinas de conteúdo mais técnico, como a Indústria Fonográfica, quando "se descobre que até mesmo para a resolução de problemas técnicos, a participação coletiva dos usuários é de fundamental importância. Tal orientação evita aos usuários os riscos de uma aplicação socialmente equivocada de seus conhecimentos técnicos", que o autor chama de "tecnocracismo".

Deste modo, o presente artigo enquadra-se nesta metodologia, caracterizandose por projetar uma solução para um problema identificado no contexto alvo onde tanto as etapas iniciais de pesquisa, quanto às etapas decisórias de construção de cenários, mobilizaram pesquisador, stakeholders, profissionais e usuários do mercado fonográfico brasileiro numa atividade prática conjunta participativa e cooperativa.

A presente pesquisa teve caráter exploratório, uma vez que permitiu uma aproximação de tendências que estão ocorrendo na realidade, para as quais não se tem ainda conhecimento sistematizado nem bibliografia consolidada. As tendências e regularidades, identificadas primeiramente na análise documental, foram sequencialmente reavaliadas na busca de se obter relações e inferências mais profundas. Juntamente com a observação participante, foram realizadas entrevistas em profundidade com stakeholders, sendo que os procedimentos e dinâmicas utilizados consistiram em análise de conteúdo, dando-se preferência por descrever, entender e compreender a visão apontada pelos entrevistados acerca do problema investigado (BARDIN, 2010).

Desta forma, a descrição e a interpretação do conteúdo obtido nas entrevistas resultaram no estabelecimento de dimensões de análise que foram relacionadas com o objetivo do presente estudo. Levando em consideração que o alvo era refletir como a Indústria Fonográfica pode redesenhar sua forma de inserir seus artistas com relevância na cena musical através da geração de cenários pela lente do Design Estratégico, realizou-se um Workshop a fim de construir subsídios para as análises 
subsequentes a partir de questões chaves observadas através da análise documental e das entrevistas com stakeholders. Com base em suas questões norteadoras, foi possível construir vínculos com outras ferramentas do design, bem como com o referencial teórico que deu lastro a este trabalho. Ao longo deste processo de coleta, tanto as análises documentais, quanto as entrevistas em profundidade, o Workshop e a projeção de cenários, proporcionaram desdobramentos que contribuíram na compreensão do processo de investigação. De acordo com Martins e Theóphilo (2009), estes dados classificados e categorizados podem ser utilizados para gerarem construtos mais abrangentes e ideias mais amplas.

Tais dimensões de análise e razões de escolha serviram como elementos centrais da estrutura para aplicação das técnicas de coleta utilizadas na etapa projetual deste trabalho. A partir das análises documentais, das entrevistas em profundidade com stakeholders, do workshop, da construção de cenários, da reflexão dos resultados e da geração de conceitos, conduzidas pela ótica do design, os resultados foram analisados sob o olhar das três capacidades do design que são: ver, prever e fazer ver, apresentadas por Zurlo (2010).

De outro lado, a inserção de contextos externos trazidos por pessoas ligadas à cena musical, sob a ótica do Design Estratégico, foi fundamental, pois apresentou três aspectos simultâneos de análise: 1) teve o objetivo de explicar as interações dos atores, 2) teve o objetivo de aplicar racionalmente as práticas espontâneas levantadas, e 3) teve um objetivo de implicar a concepção e execução da ação pelos próprios atores (MARTINS E THEÓPHILO, 2009).

\section{ANÁLISE E DISCUSSÃO DOS RESULTADOS}

O segmento da Indústria Fonográfica foi escolhido como ambiente de estudo para este artigo por estar contido em um cenário de mudanças e evoluções constantes. Além disso, o contexto atual aponta para um período de instabilidade e o que parecia ser apenas mais uma necessidade de sofisticação técnica dos produtos e serviços, acabou promovendo grande turbulência no cenário da difusão musical.

A fim de atender aos objetivos propostos, partiu-se da questão que o design proporciona contribuições estratégicas, uma vez que possui a capacidade de apresentar alternativas que facilitam a tomada de decisão. A partir desta perspectiva, foi desenvolvido o planejamento por cenários, através da construção de diferentes contextos plausíveis na perspectiva das experiências projetuais do Design Estratégico. A riqueza da construção destes cenários envolveu o conhecimento empírico do objeto de estudo que, traduzido e interpretado pelos atores do processo, tornaram-se a base para as discussões posteriores.

Seguindo a prerrogativa de que os cenários constituem uma ferramenta de previsão de direção, assim como um importante instrumento para visualizar, identificar e interpretar possíveis soluções projetuais com base no contexto empírico pesquisado, a projeção dos cenários iniciou-se pela reunião de informações. As informações, neste caso, constituem-se de pesquisas contextuais e não contextuais analisadas a partir de uma série de ferramentas, caracterizando assim, o Design Estratégico.

No contexto do presente estudo, a projeção de cenários foi a ferramenta escolhida para a definição dos concepts construídos para a identificação de 
oportunidades. A escolha da ferramenta ocorreu pelo fato da pesquisa em questão ter como objetivo investigar processos metodológicos para serem aplicados em contextos sociais complexos. Nessa perspectiva de Design Estratégico, incorporaram-se os aspectos dinâmicos presentes no design através do planejamento por cenários, uma vez que o objetivo era construir visões plausíveis de acontecerem, para que, com base nestas, fosse possível desenvolver estratégias consistentes para o futuro.

O presente trabalho construiu, primeiramente, o cenário de Fidelização em que apontou para uma valorização do conteúdo gerado pelos artistas, bem como a fidelidade em relação ao consumo de artefatos mercadológicos também desenvolvidos pelos artistas. O segundo cenário foi o de Comodidade, no qual, embora exista certa fidelidade ao artista, o consumo do trabalho dos mesmos é feito indiscriminadamente a partir de canais de mídia gratuita. Já o terceiro cenário denominado de Modismo, apontou para a valorização do conteúdo em função do contexto em questão, mas não ocorre uma fidelidade significativa a ponto de seguir de forma contínua ou prolongada algum gênero, tendência ou conceito. Por fim, o quarto cenário projetado foi o de Instabilidade que denota a volubilidade e a superficialidade do consumo de alguma obra musical.

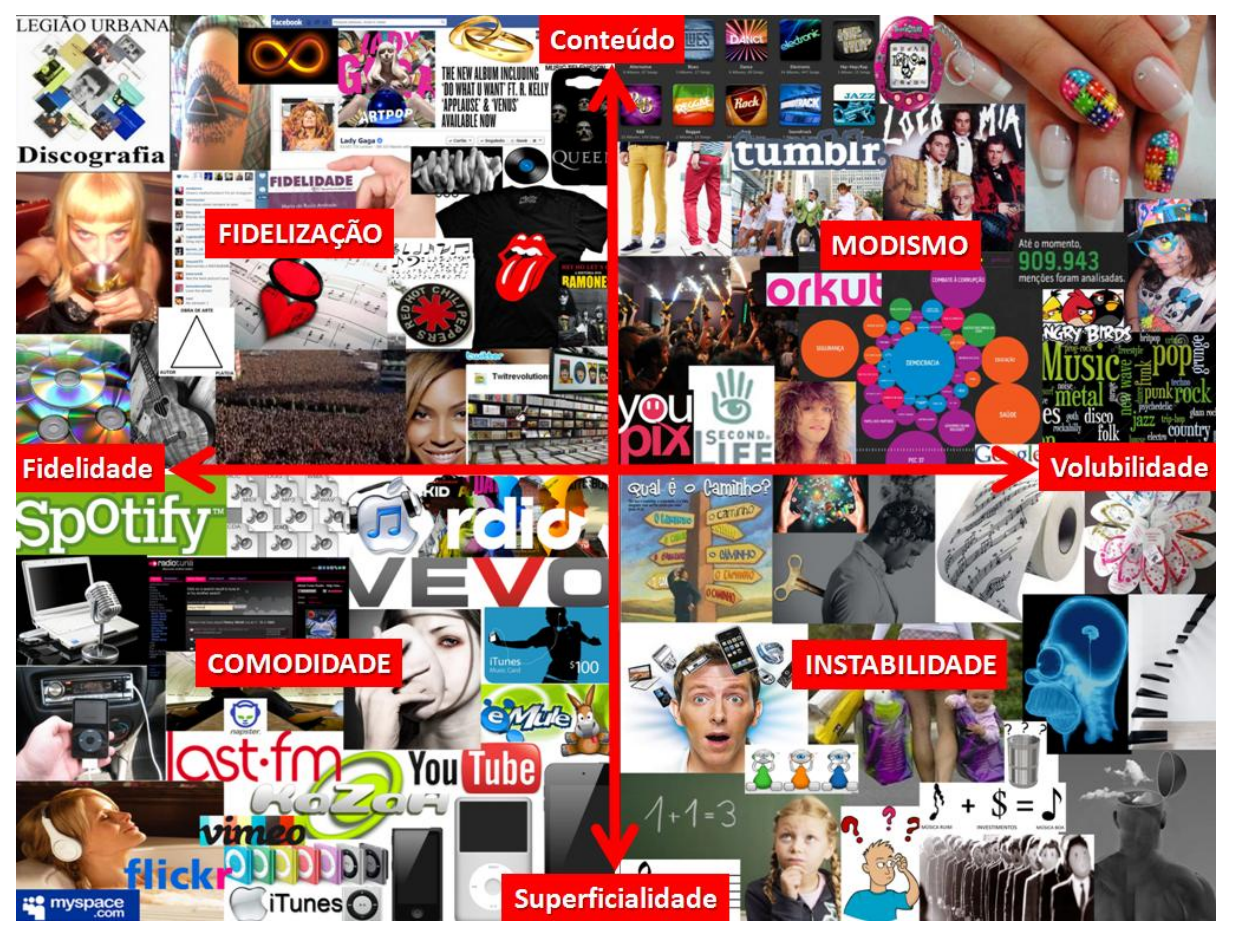

Figura 1- Cenários

Fonte: Elaborado pelos autores

Neste caso, o modelo de cenários foi considerado como uma etapa metaprojetual a partir das análises provenientes da reunião, raciocínio e processamento de informações das análises documentais, bem como das entrevistas com stakeholderes. Foram através destas análises da realidade existente, que foi possível ir além de um mero diagnóstico do passado, assim como do acompanhamento de estatísticas correntes sobre indicadores de mercados antecedentes, para a construção de pilares para a tomada de decisões e indicações acerca do futuro. 
Com isso, o instrumento adotado para a construção de cenários, foi o workshop construído, neste caso, com base em informações coletadas na análise documental e nas entrevistas em profundidade com os stakeholders. O workshop, voltado à projeção de cenários, foi utilizado a fim de criar valor organizacional com a projeção de condições necessárias para a implantação do projeto de design.

O propósito do workshop foi aprofundar as reflexões dos atores com o objetivo de gerar conteúdo para a construção de cenários de forma colaborativa em equipe, defendendo a multidisciplinaridade, uma característica do design. Além disso, foi utilizada a técnica de brainstorming onde foram apresentados percepções e pontos de vista distintos.



Figura 2 - Workshop

Fonte: Capturado pelos autores

O workshop, como etapa metaprojetual, foi trabalhado em um processo formal, sistemático e colaborativo de geração de ideias geradas por equipes multidisciplinares de indivíduos envolvidos no meio musical tais como VJs, radialistas, músicos, produtores e professores de música. Participaram ainda designers, profissionais de $\mathrm{TI}$, relações públicas, engenheiros e publicitários. Ou seja, a amostra dos entrevistados pode ser considerada diversa. Esta diversidade resultou da intenção de avaliar o objeto deste estudo em situações distintas, não homogêneas, fazendo jus à lógica de que a diversidade da amostra ajudaria a refletir as variadas facetas do ambiente da pesquisa através da narrativa empregada em diferentes momentos para dar voz ao participante e transmitir sua experiência.

Os panoramas elaborados no workshop apresentaram-se como uma espécie de laboratório projetual, em que a atmosfera, os suportes e as interfaces, foram ingredientes essenciais à geração de ideias e conceitos.

A partir de então, os cenários propostos sugeriram subsídios para reduzir as incertezas inerentes ao negócio, uma vez que os cenários proporcionaram o 
enriquecimento do debate sobre questões críticas relacionadas ao futuro da Indústria Fonográfica.

\section{CONSIDERAÇÕES FINAIS}

O estudo investigou novos cenários para a Indústria Fonográfica pela lente do Design Estratégico a partir de análises documentais, observação participante e entrevistas com stakeholders que atuam na área. Para tanto, foi necessário, além de entender as variáveis que fazem parte do ambiente que abrange a Indústria Fonográfica, compreender as avaliações dos envolvidos relacionados a este contexto.

Desta forma, em todas as etapas de análise do presente estudo foram envolvidas diversas disciplinas em um mesmo projeto, proporcionaram reflexões multidisciplinares através do diálogo aberto com outras áreas do conhecimento. Oportunizou ainda, através de suas ferramentas, a facilidade de comunicação entre os diferentes atores e disciplinas, além de proporcionar uma reflexão ampla sobre o problema do projeto.

O Design Estratégico mostrou-se, através da projeção de cenários, um instrumento motivador para a competência projetual apoiada na construção de subsídios para a formulação e desenvolvimento de estratégias de negócios. Ao longo do trabalho, foi possível perceber propostas de soluções flexíveis factíveis de serem construídas e adaptadas ao conjunto de situações que compõem um determinado cenário, apresentando propostas de respostas adequadas ao contexto estudado.

A incorporação de habilidades de resoluções criativas para problemas referentes às iniciativas estratégicas da Indústria Fonográfica fundamentou a utilização do Design Estratégico nas avaliações para a elaboração de cenários. No ambiente de constantes mudanças pelo qual passa a Indústria Fonográfica, é fundamental a habilidade de adequar e adaptar um modelo de negócios, sob o risco de perda do mercado ou até inviabilização o negócio.

Neste sentido, a geração de cenários representa uma nova fonte de vantagem competitiva considerando que pode resultar na criação de valor organizacional e na mudança da forma de fazer negócio, tornando-se um novo padrão para o surgimento de novos empreendimentos de sucesso.

O desenvolvimento de novos cenários deve considerar o novo ambiente de negócios caracterizados pelo ritmo dinâmico, descontínuo e radical de mudança, na presente pesquisa no âmbito da Indústria Fonográfica. A partir dos cenários, as organizações podem dar atenção especial a seus processos internos e de infraestrutura no intuito de que a organização crie valor, incluindo as variáveis de decisão, entre elas processos e métodos de prestação de serviços, fluxos de logística, administrativo e financeiro, além dos processos de gestão do conhecimento.

No presente estudo foi possível identificar que o Design Estratégico contribuiu na identificação de cenários através da capacidade de visão proporcionada permitindo identificar uma ideia do que se gostaria de obter a partir das análises documentais e das entrevistas em profundidade com os stakeholders. Já através do workshop, foi possível projetar panoramas para que, a partir de um correto estudo da estratégia, 
fosse possível projetar cenários para modelos de negócios com o melhor resultado possível e recursos disponíveis.

Este trabalho investigou os processos a serem desenvolvidos para lidar com a incerteza e a instabilidade do contexto atual da Indústria Fonográfica. O design, neste sentido, contribuiu com a avaliação das oportunidades face ao suporte empregado nas análises estratégicas, incorporando os riscos e as interferências externas.

Portanto, nesta etapa de conclusão, é necessário retomar a principal motivação para realizar este estudo, que consistiu em transformar o seu conhecimento tácito em conhecimento explícito, a respeito de um tema que ainda não possui um direcionamento claro em relação ao seu futuro, a Indústria Fonográfica.

O processo de coletar e organizar os dados, contextualizar e encontrar um sentido para eles, transformando-os em informação, foi o primeiro aprendizado. Posteriormente, interagir com estas informações, a partir da absorção de seus conteúdos ou como poderiam relacionar-se, oportunizou a criação de um sistema de crenças, que podem ser chamadas de conhecimento; agora, não mais tácito, mas explícito. Este sistema de crenças conduziu então à reflexões sobre o problema de pesquisa, que realizou uma análise em relação à contribuição do Design Estratégico para a identificação de cenários para a Indústria Fonográfica.

Cabe salientar que o presente estudo, apesar de trabalhar cenários de maneira complexa, atuou somente nas dinâmicas intangíveis ao segmento, bem como pelas práticas do Design Estratégico. Isso porque, para trabalhar de maneira mais aprofundada nas dinâmicas tangíveis, seria necessário um escopo de trabalho mais profundo em outras áreas do conhecimento para uma avaliação de gestão em relação ao segmento e seus comportamentos de consumo.

Existem aspectos presentes nesta pesquisa que podem ser aprofundados em estudos futuros, principalmente na forma de utilizar o Design Estratégico em relação ao desenvolvimento de novos produtos, serviços e também em relação à comunicação e às experiências alusivas à Indústria Fonográfica.

Entretanto, o estudo somente em relação ao contexto da Indústria Fonográfica para a projeção de modelos de negócio não deve ser um limitador para futuras pesquisas em relação às contribuições do Design Estratégico, contribuições estas no sentido de gerar cenários que permitam desenvolver novos modelos de negócios. Como oportunidade, destacam-se possíveis aprofundamentos incorporando elementos de outras áreas do conhecimento que envolvam gestão e estratégia como insumos para os processos que envolvam as análises metaprojetuais e PSS do Design Estratégico.

\section{REFERÊNCIAS}

AAKER, David A. Administração estratégica de mercado. Porto Alegre: Bookman, 2001.

BARROS, Carla; ROCHA, Everardo. Dimensões culturais do marketing: teoria antropológica, etnografia e comportamento do consumidor. Revista de Administração de Empresas, São Paulo, v. 46, n. 4, p. 36-47, 2006.

BORBA, Gustavo Severo de; REYES, Paulo Belo. Inovação orientada pelo design: a construção de uma organização voltada para a Inovação. In: CONGRESSO 
INTERNACIONAL DE PESQUISA EM DESIGN, 4., 2007, Rio de Janeiro. Anais. Rio de Janeiro: ANPED, 2007.

DENIS, Rafael Cardoso. Uma introdução à história do design. São Paulo: Edgard Blücher, 2000.

IFPI - Representing the recording industry worldwide. Disponível em http://www.ifpi.org >. Aceso em 10.04.2014.

HOBSBAWM, Eric. J. Os trabalhadores pobres. In.: HOBSBAWM, E. J. A era das revoluções: 1789-1848. 4 ed., Rio de Janeiro: Paz e Terra, 1982.

MARTIN, Roger. The design of business: Why design thinking is the next competitive advantage. Boston: Harvard Business, 2009.

MARTINS, Gilberto de Andrade; THEÓPHILO, Carlos Renato. Metodologia da investigação científica para ciências sociais aplicadas. São Paulo: Editora Atlas, 2ạ. Ed., 2009.

MERONI, Anna. Strategic design: where are we now? Reflection around the foundations of a recent discipline. Strategic Design Research Journal, v.1 n.1, Dec 1, p.31-38, 2008.

MOZOTA, Brigitte Borja de. Design management - using design to build brand value and corporate innovation. New York: Allworth Press, 2003.

OECD. Manual de Oslo Paris, 1998.

THIOLLENT, Michel. Pesquisa-ação nas Organizações. São Paulo: Atlas, 1997.

TIDD, Joe; BESSANT, John; PAVITT, Keith. Gestão da Inovação. 3a. ed. Bookmann, 2008.

TIGRE, Paulo Bastos. Gestão da Inovação: a economia da tecnologia no Brasil. Rio de Janeiro: Elsevier, 2006.

SCHUMPETER, Joseph. A. Teoria do desenvolvimento econômico: Uma Investigação sobre lucros, capital, crédito, juro e ciclo econômico. São Paulo: Nova Cultural, 1982.

UNEP - United Nations Environment Programme. Product-Service Systems and Sustainability: Opportunities for Sustainable Solutions. INDACO Department, Politecnico di Milano, Milão: 2004.

ZOTT, Christoph.; AMIT, Raphael. Business Model Design: An Activity System Perspective. Long Range Planning, v. 43, n. 2-3, p. 216-226. Elsevier Ltd, 2009.

ZURLO, Francesco. Della relazione tra strategia e design: note critiche. In: P. BERTOLA; E. MANZINI, Design Multiverso: Appunti di fenomenologia del design. Milano, Edizioni POLI.design, 2006.

ZURLO, Francesco. Design Estratégico. Working Paper. 2010. 